\title{
A POLÍTICA DO MOVIMENTO ESCOLA SEM PARTIDO E SEUS IMPACTOS NOS CONTEÚDOS DE CIÊNCIAS E BIOLOGIA NA EDUCAÇÃO BÁSICA
}

\author{
THE POLITICS OF THE UNPOLITICAL SCHOOL AND ITS IMPACTS ON \\ THE CONTENTS OF SCIENCE AND BIOLOGY IN BASIC EDUCATION'S
}

\author{
Marina Silveira Bonacazata Santos ${ }^{1}$ \\ Fabiana Aparecida de Carvalho ${ }^{2}$
}

\begin{abstract}
Resumo: O presente artigo analisa teoricamente os impactos do programa Escola Sem Partido (ESP) nos conteúdos das disciplinas de Ciências e Biologia na Educação Básica. Parte de uma pesquisa documental dos sites do movimento, das bases contidas em Projetos de Lei (PL) em tramitação e da revisão de literatura para se diagnosticar, primeiramente, a sua origem, e, em seguida, os impactos pra o Ensino de Ciências e Biologia. São apontados alguns conteúdos do Ensino Fundamental e Médio que sofrerão restrições com as proposições do ESP, em destaque: Origem da Vida e do Universo, Darwinismo, Ecologia e Educação Ambiental, Corpo, Sexualidade, Gênero, Diversidade Cultural, Etnia e Raça, Tecnologias de Vacinação, Prevenção e Tratamentos de Saúde. O ESP visa um Ensino de Ciências e Biologia acrítico, baseado apenas na transmissão de conteúdos e sem o favorecimento de debates plurais com professores/as e alunos/as. Por essa lógica, torna-se um perigo à liberdade nas escolas e ao conhecimento científico crítico e engajado.
\end{abstract}

Palavras-chave: Ensino Fundamental e Médio; Ensino de Ciências e Biologia; Políticas Educacionais.

\begin{abstract}
This article aims to analyze the impacts of the Unpolitical School Program (ESP) on the contents of Science and Biology subjects in basic education's. It starts with a documental analysis of the movement's websites, the bases contained in Law Projects (PL) in progress and the literature review to diagnose, first, their origin, and then, the impacts for the Science and Biology Education. Some contents of Elementary and High School are pointed out that restrictions with the proposals of ESP, in highlight: Origin of Life and the Universe, Darwinism, Ecology and Environmental Education, Body, Sexuality, Gender, Cultural Diversity, Ethnicity and Race, Vaccination Technologies, Prevention and Health treatments. ESP aims at teaching uncritical Sciences and Biology, based only on the transmission of content and without the favoring of plural debates with teachers and students. By this logic, it becomes a danger to freedom in schools and to critical and engaged scientific knowledge.
\end{abstract}

Keywords: Elementary and High School; Unpolitical School; Science and Biology Education; Educational Politics.

\footnotetext{
${ }^{1}$ Licenciada e Bacharel em Ciências Biológicas pela Universidade Estadual de Maringá (UEM). Mestranda em Educação para a Ciência e a Matemática pela Universidade Estadual de Maringá (UEM), Maringá, Paraná, Brasil. E-mail: marina bonacazata@ hotmail.com

${ }^{2}$ Doutora em Educação para a Ciência e a Matemática pela Universidade Estadual de Maringá (UEM). Professora Adjunta do Departamento de Biologia da Universidade Estadual de Maringá (UEM), Maringá, Paraná, Brasil. E-mail: facarvalho@uem.br
} 


\section{Introdução}

O presente trabalho, em caráter teórico, objetivou analisar as implicações do Movimento/Organização Escola sem Partido (ESP) e de seus Projetos de Lei (PL), que circulam no Congresso Nacional, focando, especificamente, em seus possíveis impactos em relação aos conteúdos do Ensino de Ciências e de Biologia, com vias a apontar a periculosidade do Movimento para a liberdade de expressão, liberdade de ensino e de cátedra nas escolas da Educação Básica.

Nesse âmbito, partimos da digressão da evolução histórica e do surgimento do ESP no cenário político brasileiro, pontuando suas implicações gerais para a docência, para alguns conteúdos em Ciências e Biologia e para a formação da cidadania. A proposta da investigação se deu via a análise documental dos sites do Movimento ${ }^{3}$, postagens e dos principais PL em tramitação no Congresso Nacional, que se soma a um recorte bibliográfico de textos e pesquisas realizados sobre o ESP e ao apontamento crítico daquilo que, a nosso ver, fica comprometido no ensino das áreas científicas com as investidas discursivas e as estratégias de convencimento do movimento.

Concordamos com diversos/as pesquisadores/as (CARVALHO; POLIZEL; MAIO, 2016; SOUZA et al., 2016, BAGDONAS; AZEVEDO, 2017; SILVA et al., 2018) que enfatizam o caráter de antimovimento social e persecutório do ESP, denunciando a perseguição aos/as educadores/as e aos temas sociais e escolares, especialmente aqueles que necessitam da formação crítica dos/as estudantes, da apreensão dos conteúdos científicos, do conhecimento de fatos e das verdades históricas, das proposições curriculares e das explicações escolares que se adensam nas compreensões da vida política na sociedade. O movimento traveste-se de um posicionamento apartidário para tentar impor nas escolas, via alterações da legislação educacional, entendimentos enviesados, pseudocientíficos e amparados em convicções morais e religiosas das famílias dos/as estudantes. Tais amparos podem minimizar a construção participativa da democracia escolar e abrir prerrogativas para a interferência privada no âmbito público do ensino.

São apontados alguns conteúdos do Ensino Fundamental e Médio que sofrerão restrições com as proposições do ESP, em destaque: Origem da Vida e do Universo,

\footnotetext{
3 Os sites mantidos pelo ESP podem ser acessados nos seguintes endereços: https://www.programaescolasempartido.org e http://www.escolasempartido.org, como também na Rede Social Facebook: https://pt-br.facebook.com/escolasempartidooficial/
} 


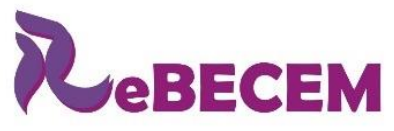

DOI: http://dx.doi.org/10.33238/ReBECEM.2019.v.3.n.3.23389
Revista Brasileira de Educação em

Ciências e Educação Matemática

ISSN 2594-9179

Darwinismo, Ecologia e Educação Ambiental, Corpo, Sexualidade, Gênero, Diversidade Cultural, Etnia e Raça, Tecnologias de Vacinação, Prevenção e Tratamentos de Saúde. Esperamos que a discussão aqui apresentada contribua para a formação de uma postura crítica e de embate docente diante das propostas do ESP, especificamente junto à aqueles/as educadoras/es que lidam com os conteúdos científicos que se entrecruzam com as questões sociais dentro das escolas da Educação Básica e com o Ensino de Ciências e Biologia.

\section{Origem e Caráter Ideológico do Movimento ESP}

O ESP veio à tona em 2004, ainda que sem muita expressividade, no cenário político e educacional do país, tendo como mentor o advogado paulista Miguel Nagib e inspiração estadunidense com a compilação de propostas da Organização "No indocrination" e de políticas de vigília aos conteúdos curriculares apresentadas por pais e mães de alunos contrários à circulação de ideias políticas nas escolas. Da mesma maneira apregoada pelo movimento norte americano, o ESP visa, desde sua fundação, acabar com o que denominam de doutrinação nas escolas. Segundo Carvalho (2019), os ideários de Nagib cruzam-se, posteriormente, com as proposições de Olavo de Carvalho, um ferrenho defensor de valores conservadores e da retomada da moralidade cristã como estratégia de combate a uma suposta influência marxista nas escolas.

Nesse período, entretanto, o ESP não teve muita visibilidade e aceitação, principalmente, por ter sido considerado a plataforma de um grupo restrito e uma proposição absurda a tentar derrubar os currículos escolares e as liberdades de expressão, ensino e cátedra de educadores/as.

O movimento, porém, ressurge mais forte como bandeira política em 2013, quando deputados/as religiosos/as (distribuídos em Frentes Parlamentares diferenciadas) passaram a apoiar movimentos difusos nas ruas cobrando ações políticas contra o segundo mandato do Governo Dilma Rousseff (2015-2016) e a se coligarem com o então Deputado Federal Jair Bolsonaro. Como PL no 2974/2014, a proposta do ESP foi apresentada à primeira vez, na Assembleia Legislativa do Rio de Janeiro, pelo deputado Flávio Bolsonaro. E, na segunda vez, como PL nº 867/2014, na Câmara Municipal do Rio de Janeiro, pelo vereador Carlos Bolsonaro, o que também expõe, de acordo com Carvalho (2019), o vínculo de Miguel Nagib com a família Bolsonaro e como bandeira política da atual gestão do país (2019-2022). 
DOI: http://dx.doi.org/10.33238/ReBECEM.2019.v.3.n.3.23389

No mesmo ano, o movimento alçou um status mais significativo com o auxílio das divulgações promovidas nas redes sociais da internet e com a perseguição ao "Projeto Escola sem Homofobia", do Ministério da Educação (MEC), que visava promover o respeito à diversidade sexual a partir da escola ${ }^{4}$ (SILVEIRA, 2017), mas, negativamente, ganhou a alcunha de "Kit Gay" por intermédio da ação ativista de grupos religiosos católicos e neopentecostais. O enfraquecimento dessa política educacional e da tentativa de uma Educação Sexual voltada para o combate à LGBTfobia foi circunstancial para a emergência do ESP no cenário político e escolar brasileiro.

Para Miguel (2016, p. 601),

com ataques e ações virtuais, por vídeos e inserções em espaços públicos e parcerias com 'ícones' da comunidade conservadora Brasileira, a confluência foi facilitada graças ao trabalho de propagandistas da extrema direita, em particular os alinhados a Olavo de Carvalho, para quem a dissolução da moral sexual convencional é um passo da estratégia comunista.

Esse apelo a uma estratégia comunista disseminada pelas esquerdas cresceu como a discursividade ${ }^{5}$ central do ESP. Nesse tocante, os anos de 2014 e de 2015 marcaram o estabelecimento do ESP, principalmente, por meio das pressões exercidas por parlamentares coligados a Nagib e a igrejas durante a votação dos Planos de Educação aos níveis Federal, Estadual e Municipal. Tais políticos/as elegeram temáticas como: Gênero, Diversidade Sexual e Cultural, Etnia, Raça e Pertencimento Cultural como temas contundentes, de caráter comunista, que afrontam a moral das famílias brasileiras, devendo, de acordo com seus entendimentos, serem sistematicamente combatidos e banidos das escolas. A vinculação da organização com partidos acarretou as alterações no Plano Nacional de Educação (2014-2024) quanto às metas que instrumentam as políticas públicas e conteúdos curriculares referentes a Gênero, Sexualidade e Diversidade (CARVALHO; POLIZEL; MAIO, 2016), abrindo precedentes para se impactar os materiais didáticos das escolas, as provas de concursos, as instituições de ensino superior (IES), a formação e os atributos docentes para a liberdade de ensino.

A estratégia de convencimento e o argumento mais usado pelos/as defensores/as do ESP na elaboração de seus PL é o apelo ao fato de que materiais didáticos e,

\footnotetext{
${ }^{4}$ O Projeto Escola sem Homofobia começou a ser produzido em 2008, tendo como parceiros: a Associação Brasileira de Lésbicas, Gays, Bissexuais, Travestis e Transexuais (ABGLT), o Ministério da Educação e Ministério da Saúde. Por pressões de parlamentares conservadores/as e religiosos/as, o Governo Dilma Rousseff, em 2011, vetou o Brasil sem Homofobia.

${ }^{5}$ Por discursividade, entendemos uma série de discursos, narrativas, práticas e enunciados que criam representações, estereótipos, posições ideológicas que se correlacionam com a criação de significados e com as relações de poder (CARVALHO; POLIZEL; MAIO, 2016).
} 
DOI: http://dx.doi.org/10.33238/ReBECEM.2019.v.3.n.3.23389

particularmente, professores utilizariam de estratégias de doutrinação em sala de aula, abusando da audiência cativa de alunos/as ${ }^{6}$ e de uma suposta ingenuidade dos/as estudantes para instalarem suas posições pessoais, bandeiras militantes e subterfúgios para a arregimentação esquerdo-partidária nas escolas. Segundo o Website do movimento,

a doutrinação política e ideológica em sala de aula ofende a liberdade de consciência do estudante; afronta o princípio da neutralidade política e ideológica do Estado; e ameaça o próprio regime democrático, na medida em que instrumentaliza o sistema de ensino com o objetivo de desequilibrar o jogo político em favor de um dos competidores (ESCOLA..., 2019, s/p).

Valendo-se, portanto, da discursividade: "Professor/a - doutrinador/a comunista", o ESP está a criar estratégias de convencimento e frentes de representação que visam, entre outras questões, interferir nos livros didáticos distribuídos pelo governo, nos Planos de Educação em vigência, na aplicação da Base Nacional Comum Curricular (BNCC) e na alteração da Lei de Diretrizes e Bases da Educação (LDBEN/1996) para alteração de seu conteúdo e instituição do movimento como um programa educacional e uma política de Estado.

No ano de 2015, o Deputado evangélico Izalci Lucas protocolou na Câmara dos Deputados o PL n 867, que propõe a inserção da ESP na LDBEN/1996 e funda um estatuto de deveres dos/as professores/as nas escolas que, num primeiro momento, pode ser entendido como boa proposição e como uma cartilha de defesa dos/as estudantes, mas, perscrutando suas minúcias, percebemos um apelo ao não e às proibições da livre manifestação do pensamento. E, em 2016, o Pastor Magno Malta apresenta no Senado o PL n⿳0 193, que também defende a inclusão da ESP como política educacional ${ }^{7}$. Conforme dados disponibilizados por Annunciato (2017), o ESP está a crescer em representação nas casas legislativas do país (FIGURA 1).

\footnotetext{
${ }^{6}$ Para o ESP, estudantes não são autônomos, não pensam por si próprios, ou seja, são alunos/as passivos e vítimas fáceis da manipulação política.

${ }^{7}$ Esse PL foi retirado de pauta durante o mandato do Pastor como Senador. Entretanto, o mesmo influenciou uma série de legisladores e inspirou centenas de proposições ESP em Estados e Municípios.
} 
DOI: http://dx.doi.org/10.33238/ReBECEM.2019.v.3.n.3.23389

Figura 1: Número de Projetos de Lei ESP no País

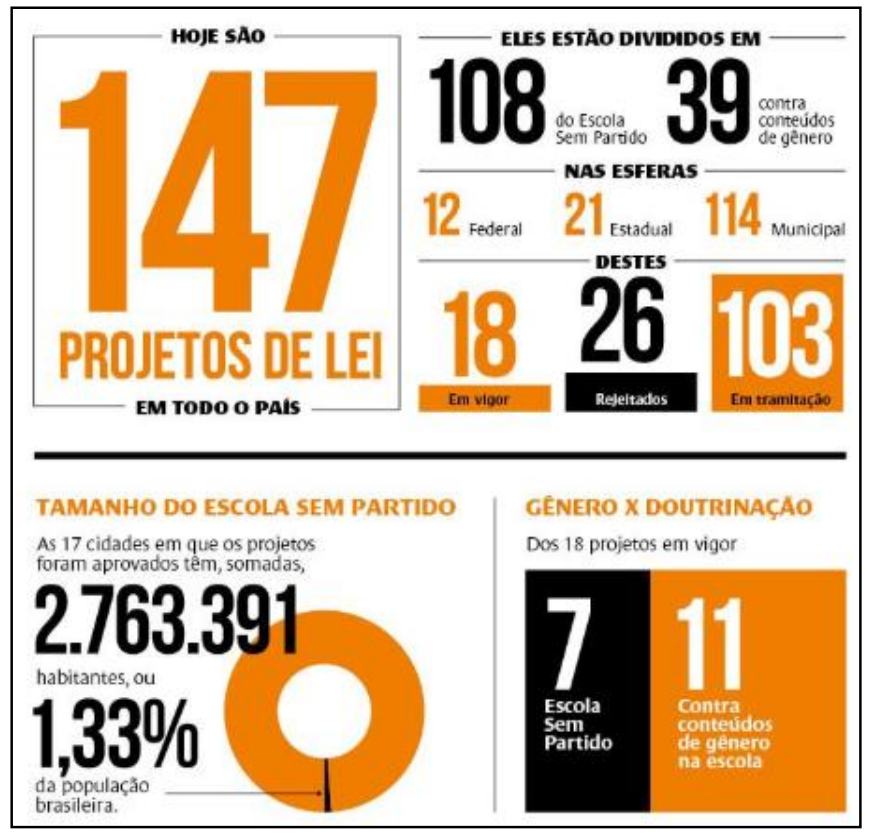

Fonte: Annunciatto (2017)

Para Demier (2017), o ESP baseia-se no conservadorismo comportamental e no reacionarismo cultural. As plataformas e as representatividades religiosas políticas são consideradas estratégicas para o seu fortalecimento, principalmente porque o movimento recebe apoio de frentes parlamentares e de bancadas tais como: a) Frente Parlamentar Evangélica, composta pelas legendas PRB, DEM, MDB, PSD e signatários das Igrejas Assembleia de Deus, Universal do Reino de Deus e Igreja Batista; b) Frente Parlamentar Mista Católica Apostólica Romana; c) Frente Parlamentar em Defesa da Vida e da Família; e d) Frente Parlamentar para a Liberdade Religiosa (SILVEIRA, 2019).

Atualmente, tramita na Câmara o PL n ${ }^{\circ}$ 246/19, de autoria da Deputada Bia Kicis, que visa autorizar legalmente as gravações das aulas para a fiscalização dos conteúdos escolares pelos familiares e punições a docentes que versarem sobre temáticas de Gênero e Sexualidade nas escolas. O PL de Kicis, conforme aponta Carvalho (2019), é considerada a proposição mais reacionária da organização desde o primeiro projeto protocolado em casas legislativas, pois visa instaurar a perseguição aos conteúdos escolares e estabelece uma estreita relação de cerceamento às atividades pedagógicas que discutam Sexualidade, Corpo e Gênero.

Fica evidente a articulação do ESP com as políticas de Estado, conservadorismo e Religião para limitar a liberdade docente nas escolas e as políticas públicas educacionais. Vale ressaltar que certos grupos religiosos conservadores são, de certo modo, céticos à produção do conhecimento crítico. Entretanto, para a garantia de seus 
DOI: http://dx.doi.org/10.33238/ReBECEM.2019.v.3.n.3.23389

espaços políticos, as facções religiosas passam a relativizar a verdade, impondo seus credos como absolutos e inquestionáveis de modo a disputar a veracidade dos fatos e as bases paradigmáticas que explicam o mundo com os conhecimentos aceitos e explicados pela ciência, colocando, sumariamente, os princípios da laicidade nas escolas e a autonomia do campo educacional em xeque, principalmente com a disseminação de concepções infundadas e interpretações falaciosas dos fatos históricos e científicos.

Essa plataforma ideológica também está enfaticamente delineada nas proposições do ESP em seu Website. Logo, o quê o movimento aponta como objetivo é o propósito de: "implantar um projeto de lei, que visa combater a doutrinação de pensamento realizada por professores em sala de aula, garantindo que o aluno tenha a liberdade de escolha, liberdade religiosa, opinião própria, entre outros quesitos" (ESCOLA..., 2019, $\mathrm{s} / \mathrm{p})$.

Disseminando a ideia de uma suposta doutrinação, o ESP usa de outra estratégia/discursividade e torna obrigatória a afixação em todas as salas de aula do Ensino Fundamental e Médio de um cartaz com os "Deveres do Professor", conforme previsto nos Artigos redigidos nos diversos PL da organização. Dentre os deveres do/a professor/a estão a não indução do/a aluno/a para seguir os seus pensamentos, ideologias, devendo o/a mesmo/a respeitar a posição de estudantes e suas opiniões morais e religiosas. Assim, o/a professor/a:

1) não se aproveitará da audiência cativa dos alunos para promover os seus próprios interesses, opiniões, concepções ou preferências ideológicas, religiosas, morais, políticas e partidárias;

2) não favorecerá nem prejudicará ou constrangerá os alunos em razão de suas convicções políticas, ideológicas, morais ou religiosas, ou da falta delas;

3) não fará propaganda político-partidária em sala de aula nem incitará seus alunos a participar de manifestações, atos públicos e passeatas;

4) ao tratar de questões políticas, socioculturais e econômicas, o professor apresentará aos alunos, de forma justa - isto é, com a mesma profundidade e seriedade -, as principais versões, teorias, opiniões e perspectivas concorrentes a respeito da matéria;

5) respeitará o direito dos pais dos alunos a que seus filhos recebam a educação religiosa e moral que esteja de acordo com suas próprias convicções;

6) não permitirá que os direitos assegurados nos itens anteriores sejam violados pela ação de estudantes ou terceiros, dentro da sala de aula (BRASIL, 2019, $\mathrm{s} / \mathrm{p})$.

Esses pressupostos indeterminam a liberdade de apresentar os conteúdos escolares, pois, ao mesmo tempo em que se têm uma escola dita plural, fixa-se o "imperativo do não", uma escola da censura e da proibição.

Por essa lógica, nenhum docente poderá expor ou debater em sala de aula temas advindos de questões políticas, sendo impedido e proibido de discutir a importância da 
DOI: http://dx.doi.org/10.33238/ReBECEM.2019.v.3.n.3.23389

participação dos/as alunos/as em movimentos populares, em atos públicos, em grêmios escolares, em passeatas, ou, de construir a opinião crítica em sala de aula e de se expressar sobre temas sociais contundentes, devendo, acima das proposições dos conteúdos escolares determinados em diretrizes, documentos e no projeto político pedagógico escolar, prevalecer a convicção religiosa e moral de acordo com a vontade familiar (CARVALHO; POLIZEL; MAIO, 2016). Eis o perigo da instauração de uma verdade única na escola, pois, no que concerne ao ensino das áreas de conhecimento, o ESP restringe o que chama de temas contundentes e conflituosos, que demandam várias posições de pensamento, compreensões sociais e históricas, à verdade dos grupos hegemônicos e a uma espécie de adulteração das explicações científicas com base em fakenews $^{8}$ (CARVALHO, 2019).

O movimento ainda declara que as escolas deverão apresentar e entregar às famílias materiais informativos que possibilitem a monitoria e a vigília do ensino dos conteúdos considerados contundentes ou de cunho social. Tal postura oprimirá os debates em salas de aula e implicará em restrições ao ensino das áreas do conhecimento, com mais impacto aos temas científicos mobilizados pelo Ensino de Ciências e Biologia.

\section{Implicações do ESP para o Ensino de Ciências e Biologia}

Pensando especificamente nos currículos de Ciências e de Biologia, implica o ESP em tomar como contundentes temáticas como: Educação Ambiental, uso da Ciência e da Tecnologia na sociedade, Origem e Evolução da Vida, Corpo, Gênero e Sexualidade, entre outras. Essas temáticas correm o risco de serem lidas por pensamentos do senso comum, pseudocientíficos e conduzidas de maneira enviesada pela visão moral e religiosa de muitos/as pessoas e familiares. A adoção do ESP acarretaria impactos à Alfabetização Científica e cultural de estudantes do Ensino Fundamental e Médio, pois o seu programa educacional e seus códigos de preceitos afetam, diretamente, conteúdos que requerem a compreensão das bases científicas para a nossa vivência em sociedade.

Segundo a Constituição Federal (BRASIL, 1988), a liberdade de expressão é garantida por lei e todas as pessoas têm a prerrogativa de viver esse direito.

\footnotetext{
${ }^{8}$ Fakenews são interpretações distorcidas de fatos, acontecimentos e notícias. Apelam para a emoção dos espectadores/as e receptores/as das informações que, por sua vez, não possuem muito discernimento sobre a realidade e sobre os contextos políticos. Podem conter explicações e dados falsos sobre a história, a política e, até mesmo, sobre a Ciência, contrapondo dados manipulados aos dados estatísticos e científicos produzidos por órgãos idôneos e confiáveis.
} 


\begin{abstract}
Art. $5^{\circ}$ Todos são iguais perante a lei, sem distinção de qualquer natureza, garantindo-se aos brasileiros e aos estrangeiros residentes no País a inviolabilidade do direito à vida, à liberdade, à igualdade, à segurança e à propriedade, nos termos seguintes: (...)

VI - é inviolável a liberdade de consciência e de crença, sendo assegurado o livre exercício dos cultos religiosos e garantida, na forma da lei, a proteção aos locais de culto e suas liturgias; (...)

VIII - ninguém será privado de direitos por motivo de crença religiosa ou de convicção filosófica ou política, salvo se as invocar para eximir-se de obrigação legal a todos imposta e recusar-se a cumprir prestação alternativa, fixada em lei (BRASIL, 1988, s/p).
\end{abstract}

Logo, com base na Carta Magna, ninguém pode ser proibido de se expressar, de ter sua liberdade de ensino e de cátedra vigiadas e punidas porque o ESP postula que os conteúdos escolares, que são coletivos e amparados por documentos educacionais e como currículos escolares, devem ser escolhidos por opiniões, representações, representantes e convicções de foro privado e particular, situadas em concepções de grupos fechados como igrejas, congregações, famílias e partidos políticos.

Conforme apontam Carvalho; Polizel e Maio (2016), com o advento do ESP, os docentes se sentirão ameaçados e vigiados por pedagogias de medo, práticas de delação e práticas de entreguismo por seus/suas próprios/as alunos/as e colegas. Nesse sentido, as temáticas que necessitem de senso crítico poderão ser tolhidas nas escolas, acarretando prejuízos enormes à escolarização e à consciência política da vida em sociedade.

Por outro lado, o princípio da construção da autonomia respalda aos/as docentes a apresentarem várias vertentes sobre um fato histórico, sobre uma descoberta científica, um fenômeno natural, justamente para que os/as estudantes possam se apropriar das explicações, debaterem as correntes de pensamentos e chegarem, com criticidade, àquelas interpretações que são aceitas como conhecimento escolar e científico. Diversos documentos, entre eles os Parâmetros Curriculares Nacionais do Ensino Fundamental (PCN) (BRASIL, 1997), estabelecem a importância de se ter pluralidade no ensino de qualquer disciplina:

A escola tem um papel fundamental a desempenhar nesse processo. Em primeiro lugar, porque é um espaço em que pode se dar a convivência entre estudantes de diferentes origens, com costumes e dogmas religiosos diferentes daqueles que cada um conhece, com visões de mundo diversas daquela que compartilha em família (BRASIL, 1997, p. 123).

Embora defenda, ainda que de forma restritiva, a pluralidade de ideias, O ESP pode vir a indeterminar as múltiplas visões do conhecimento e a impor uma explicação equivocada sobre as coisas (CARVALHO, 2019). Não haverá possibilidades para a 
DOI: http://dx.doi.org/10.33238/ReBECEM.2019.v.3.n.3.23389

exposição de opiniões e realizações de debates em sala de aula, o que pode acarretar na imposição de pensamentos prontos, acabados, dogmáticos e inquestionáveis. Essa corrente para o entendimento da produção da ciência não é vantajosa, já que a construção das ideias e a produção científica fazem-se por meio de indagações, questionamentos dos paradigmas, dos modelos explicativos, com o uso de tecnologias de vivência, de informação e de comunicação, com o debate e a coletivização dos conhecimentos e com a visão crítica dos próprios usos das ciências e da escola.

Contrariando a postura aberta e dialógica da escola democrática, a ideologia do ESP busca o/a professor/a neutro/a, que deverá expor os assuntos sem demonstrar os prós e os contras em torno de uma questão, ou seja, o/a educador/a, de acordo com as concepções do movimento, terá o papel de apenas transmitir informações técnicas e conteudísticas para os/as discentes.

Sabemos que os conhecimentos não são neutros. Entretanto, o ESP insiste na falácia de neutralidade, apesar da impossibilidade de uma visão imparcial sobre as coisas. As escolas, portanto, prescindem necessariamente de pontos de vista diferentes, principalmente em assuntos científicos que demandam ou corroboram para a criação de um problema e o levantamento de hipóteses para resolver questões ou se entender processos de descobertas na humanidade.

Conforme aponta Vygotsky (1989), o ambiente escolar é visto como ideal para se desenvolver o pensamento científico, pois permite que haja o confronto de experiências imediatas e conhecimentos cotidianos com os saberes acumulados pela vivência, ocorrendo, portanto, a elaboração de abstrações e generalizações dos conceitos científicos.

A neutralidade do ESP está alinhada ao ensino tradicional, no qual o importante é que o aluno apenas decore o conteúdo. Essa visão de ensino deve ser superada, pois se é preciso haver contestação, divergência, debate livre de ideias, relações com outras explicações para que se conforme o pensamento científico dos/as estudantes.

Destacando especificamente o Ensino de Ciências e de Biologia, o ESP questiona alguns assuntos dentro da abrangência dessas áreas do conhecimento. Selles destaca que

o "Programa Escola Sem Partido" expõe uma conexão com o Ensino de Ciências e Biologia na escola, pois afeta diretamente a liberdade docente e oprime o ambiente da sala de aula. [...] Especialmente, ao ensino dos conteúdos biológicos escolares sustentados pela compreensão da evolução biológica em bases neodarwinistas, temática nada trivial por mostrar seu enraizamento epistemológico a uma teoria científica de maior significação para as Ciências Biológicas. O ensino de evolução na escola encontra-se ameaçado pelo curso da aprovação desse projeto de lei (em percursos difamatórios, inclusive à obra 


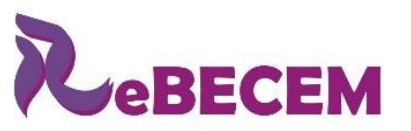

Revista Brasileira de Educação em

Ciências e Educação Matemática

DOI: http://dx.doi.org/10.33238/ReBECEM.2019.v.3.n.3.23389

de Paulo Freire) que deseja confundir direitos de aprendizagem escolar e formação crítica com mecanismos de doutrinação, reclamando valores religiosos dos alunos e de suas famílias (SELLES, 2016, p. 831-832).

Corroborando com os argumentos de que o ESP arrasta vieses determinísticos para a distorção das teorias de maior significação para a Ciência, o trabalho de Bagdonas e Azevedo (2017) destaca impactos para dois conteúdos peculiares que serão perseguidos pelo movimento: Origem do Universo e Origem da Vida Biológica.

Segundo os autores, com o advento do ESP, o conteúdo Origem do Universo pode ser retirado dos currículos, uma vez que envolve também discussões religiosas, com ênfase em teorias criacionistas e opositoras ao Big Bang. No que concerne à Origem da Vida conforme preconiza o conhecimento científico atual, as Bases Evolucionistas de Charles Darwin, que postulam ser a seleção natural das espécies as âncoras da Evolução e o elo à nossa ancestralidade, podem ser imputadas por credores/as do Livro Bíblico do Gênesis, que diz ter sido Deus o criador de todas as coisas e de todas as espécies, enfatizando o fixismo e visões distorcidas sobre a Geologia, a Física, a Química, a Geografia e a Biologia da Terra.

Nesse quesito, Bagdonas e Azevedo (2017), alertam para o perigo de o Evolucionismo e o Criacionismo serem ensinados como sinônimos, sem a possibilidade de discutir as incoerências em ambas as teorias, as evidências geológicas e fósseis da Evolução, as intempéries ambientais e as mutações como fatores de seleção, as correlações com outras explicações científicas, epistemológicas ou outras cosmovisões sobre a criação do mundo, uma vez que essas explicações científicas são antagônicas aos muitos conhecimentos religiosos das famílias conservadoras e dogmáticas (FIGURA 2) e aos princípios estabelecidos nos PL do movimento ESP. A proibição decorrente da moral religiosa impediria os/as estudantes a aprender com a convivência de opiniões divergentes, com o respeito, com as múltiplas linguagens, com as proposições de diferentes culturas e com a perspectiva de construção da Ciência. 
DOI: http://dx.doi.org/10.33238/ReBECEM.2019.v.3.n.3.23389

Figura 2: Postagem no Site Escola sem Partido criticando teorias denominadas de falsas, entre elas, o Evolucionismo Li o texto de Mirian Macedo. Como advogado creio que está havendo uma
inversão. Os causadores de dano moral são exatamente as escolas (ou melhor
pseudo-escolas) que ensinam não só falsas doutrinas (como é o caso do
marxismo, do evolucionismo, etc.), mas também induzem a comportamentos
morais reprováveis. Os pais que se esforçam para imprimir uma educação
hígida a seus filhos, todavia, continuarão a enfrentar dificuldades de vez que
estas fazem parte do "fenômeno" da Revolução Cultural, com a qual as
esquerdas - fracassadas na doutrinação ideológica explícita - tentam subverter
os últimos vestígios da cultura cristã. Ronaldo Ausone Lupinacci (Barreiras, BA)

Fonte: www.escolasempartido.org

Para o ESP, a Origem do Universo e a Evolução deveriam ser apresentadas como outras teorias quaisquer sem a vinculação com modelos científicos e sem o respeito aos princípios de um Estado Laico, que permite a discussão de vários conteúdos sem a imposição de uma convicção como unanimidade escolar.

Outras temáticas que perpassam os conteúdos de Ciências e de Biologia são referentes às compreensões sobre Gênero, Sexualidade, Corpo e Diversidade Sexual. O ESP considera essas temáticas doutrinárias e perigosas, enquadrando-as no que denomina de "Ideologia de Gênero".

Conforme já mencionamos, desde 2014, observa-se a retomada de forças sociais conservadoras no cenário político do país. Parte desses grupos dogmáticos, representados por líderes religiosos/as católicos/as e neopentecostais ligados ao poder político e empresarial, afirmam existir "uma conspiração internacional que quer 'perverter' as crianças, ensiná-las a ser gays e assim destruir a família considerada tradicional” (REIS, 2015, p. 1). Com o debate referente à "Ideologia de Gênero", os projetos do ESP foram modificados e ganharam uma nova normativa que determina que:

O Poder Público não se imiscuirá na orientação sexual dos alunos nem permitirá qualquer prática capaz de comprometer ou direcionar o natural desenvolvimento e sua personalidade em harmonia com a respectiva identidade biológica de sexo, sendo vedada, especialmente, a aplicação dos postulados da ideologia de gênero (ESCOLA..., 2019).

Fica evidente que o ESP restringe a conceituação, as explicações, os entendimentos e as discussões de Gênero e Sexualidade a uma perspectiva de determinismo biológico, uma vez que desconsidera as complexas dinâmicas genéticas, cromossômicas, hormonais, fisiológicas, neuronais e suas relações com a vida social, 
DOI: http://dx.doi.org/10.33238/ReBECEM.2019.v.3.n.3.23389

cultural e subjetiva das pessoas e se atrela à concepção religiosa sobre Gênero e Sexualidade (FIGURA 3).

Figura 3: Depoimento de Miguel Nagib sobre Evento de Sexualidade, Feminismo e Questões de Gênero organizado pela UFBA

\begin{abstract}
A obsessão dessa turma, como se sabe, é a chamada teoria (ou ideologia) de gênero. Indiferente às decisões soberanas do Congresso Nacional e da imensa maioria das Assembleias Legislativas e Câmaras de Vereadores - que se negaram a incluir a ideologia de gênero nos seus respectivos planos de educação - , a burocracia do ensino continua utilizando a máquina do Estado para promover suas próprias convicções, induzindo professores desavisados a violar o direito dos pais dos alunos sobre a educação moral dos seus filhos.

Ao cair nessa conversa, e tratar seus alunos como cobaias da teoria de gênero, esses professores estão correndo um altíssimo risco. Refiro-me à possibilidade de os pais dos estudantes entenderem que essa prática pedagógica implica algum tipo de dano aos seus filhos ou ao seu direito de dar a eles a educação moral que esteja de acordo com suas próprias convicções - direito previsto no art. 12, IV, da Convenção Americana sobre Direitos Humanos.
\end{abstract}

\title{
Fonte: www.escolasempartido.org
}

Para Scott, entretanto, o Gênero "[...] é um elemento constitutivo de relações sociais baseado nas diferenças percebidas entre os sexos, é uma forma primeira de significar as relações de poder" (1995, p. 21). Nesse sentido, podemos compreendê-lo como uma categoria de análise das igualdades, desigualdades e das condições sociais que atravessam modos de se construir masculinidades, feminilidades ou outras vivências generificadas. Muitas pessoas pensam o Gênero como uma característica meramente biológica, no entanto, ela é social e nos diz sobre como nos constituímos como pessoas. Ademais, a Sexualidade Humana não é, simplesmente, um mecanismo inato ou instintivo; ela é um mosaico de sentimentos que vão desde o desejo sexual até as múltiplas formas com as quais vivemos nossas afetividades (LOURO, 1997). É restritivo pensar a Sexualidade apenas no campo biológico da reprodução.

Para Carvalho (2019), é perigosa a potencialização teológica dos entendimentos do Gênero, justamente porque ela incorre na normatização das vivências afetivo-sexuais e numa rebiologização da diversidade sexual, tomando a heterossexualidade como única forma de ser e de se viver afetivamente.

O ESP arrasta as convicções religiosas de grupos como o PróVida, Pró Família, a Opus Dei, de documentos canônicos como o Documento da Aparecida, o Catecismo 
DOI: http://dx.doi.org/10.33238/ReBECEM.2019.v.3.n.3.23389

Católico e as pregações de pastores evangélicos que acatam o sintagma "Ideologia de Gênero" e desconsideram as lutas por igualdade e equidade para mulheres e pessoas LGBT, bem como os Estudos de Gênero, a luta por direitos das pessoas LGBT, os estudos biológicos e os estudos sociais sobre os fenômenos da vida humana (CARVALHO; POLIZEL; MAIO, 2016; JUNQUEIRA, 2017; CARVALHO, 2019). Essa orientação fundamentalista pode levar ao apagamento de diversas discussões escolares.

Assim sendo, os/as professores/as de Ciências e Biologia, por exemplo, não poderão mais discutir de forma crítica os conteúdos e as compreensões sobre o Corpo Humano e as manifestações do desejo e da afetividade. Conteúdos como Sistemas Genitais, Menstruação, Fecundação, Desenvolvimento Embrionário, Aborto (natural ou induzido), Infecções Sexualmente Transmissíveis e AIDS (IST/AIDS), Heterossexualidade, Homossexualidade, vivências saudáveis do prazer e das descobertas do corpo, Masturbação, Planejamento Familiar e Prevenção de Gravidez, Diversidade de Corpos e Diversidade Sexual seriam banidos das escolas, pois, de acordo o ESP, esses conteúdos incentivariam a iniciação precoce da atividade sexual em crianças e jovens e despertariam curiosidades indevidas para a Homossexualidade e para a distorção dos valores morais.

Nesse quesito, o movimento incentiva junto às famílias práticas de caça e de denúncias dos conteúdos escolares, a perseguição de docentes e também de livros de Ciências (FIGURA 4) que abordem o conteúdo Sexualidade, mesmo que esse ainda seja abordado sob o aspecto fisiológico da organização dos Sistemas e da Corporeidade. 
DOI: http://dx.doi.org/10.33238/ReBECEM.2019.v.3.n.3.23389

Figura 4: Depoimento com a denúncia de uma mãe sobre a Educação Sexual em livros didáticos de Ciências

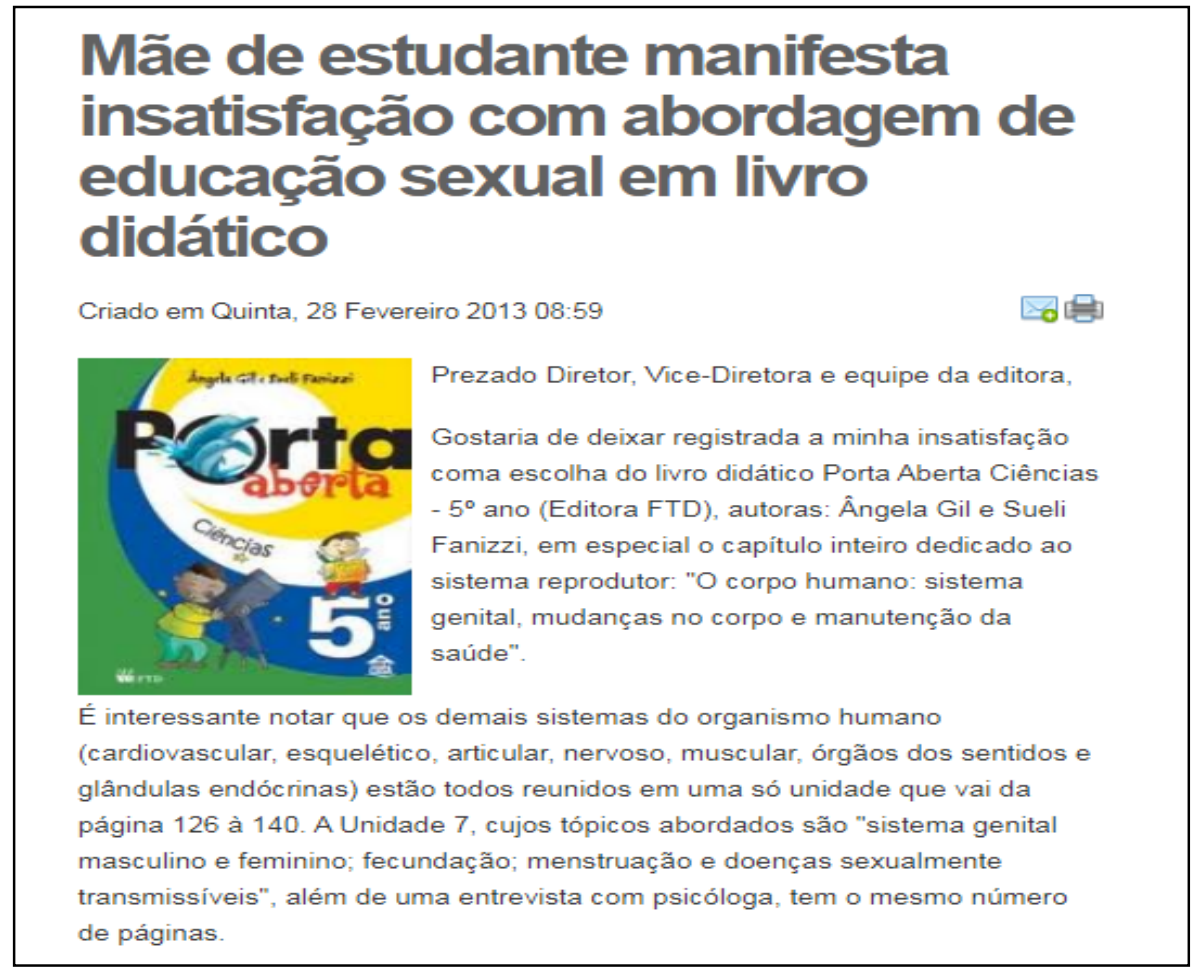

Fonte: www.escolasempartido.org

Sabemos que a Educação Sexual para as crianças e jovens é fundamental por diversos motivos já apontados pelos documentos educacionais e por pesquisadores/as da área de Ensino de Ciências e Biologia, entre os quais estão: a) a conscientização para o respeito com o próprio corpo e os corpos de outras pessoas; b) a superação das desigualdades de Gênero; c) a Prevenção de IST/AIDS e Gravidez não planejada (BRASIL, 1997; LOURO, 1997); d) a superação do fisiologismo, dos tabus quanto à Sexualidade, o respeito à diversidade, o combate à LGBTfobia e todos os tipos de preconceito (ALTMANN, 2001; CARVALHO; BERTOLLI-FILHO, 2011); e) o combate à violência contra mulheres, o assédio sexual e ao estupro (LOURO, 1997; MAIO, 2018).

Entretanto, o apego às convicções morais é um impedimento para as discussões desses temas com criticidade, para a compreensão dos fatores sociais que incidem nos dados que conformam as desigualdades entre mulheres e homens e os índices das violências LGBTfóbicas, para o conhecimento de medidas profiláticas, preventivas e educativas para se evitar infecções e doenças, para se abordar direcionamentos sobre a gravidez e sobre as vivências respeitosas e consentidas das sexualidades, entre outras questões. 
DOI: http://dx.doi.org/10.33238/ReBECEM.2019.v.3.n.3.23389

Trata-se, por efeito, de um impedimento de se tratar da própria vida biológica, pois muitas de suas manifestações se expressam através do sexo, da Sexualidade, da afetividade, da reprodução e da associação de duas pessoas que podem ou não se relacionarem de maneira sexuada ou afetiva.

Nesse sentido, o apagamento da Educação Sexual, dos Gêneros, das Sexualidades é também um apagamento sobre a vida humana, sobre a biologia dos seres e sobre a importância de nossos Sistemas Genitais. Gera uma alienação da realidade das vivências entre pessoas e pode sustentar mais ainda, junto aos/as estudantes, a manifestação de preconceitos direcionados às pessoas diferentes, às pessoas LGBT e às pessoas que não se enquadram nos descritores reprodutivos e canônicos da Sexualidade.

Outro tema relevante para o Ensino de Ciências e Biologia que vem sofrendo ataques dos posicionamentos do ESP é a Educação Ambiental. Os/as professores/as costumam abordar esse assunto numa perspectiva ecológica, dimensionando aos/as alunos/as a importância do respeito para com o meio ambiente em questões como: a) Desenvolvimento Sustentável; b) Impactos Ambientais (poluição, degradação, interferência antrópica); c) Modificações no Clima e Aquecimento Global; d) Processos de extinção de seres vivos gerados por seres humanos; e) Processos de modificações nos Biomas pelo agronegócio; f) Conservação e Preservação, entre outros.

Embora a Educação Ambiental seja um direito assegurado constitucionalmente, e também pelo Sistema Nacional de Meio Ambiente (SISNAMA), pelos documentos e diretrizes educacionais e vista como uma medida importante para a conscientização de escolares quanto aos problemas ambientais, muitos pais e mães, sob a influência das proposições do ESP, também não veem relevância nas abordagens ecológicas nas escolas.

Tal posicionamento soma-se ao descaso do atual Presidente da República, Jair Bolsonaro, apoiador do movimento ESP, com a questão ambiental. Obviamente, outros/as governantes tiveram incoerências em suas gestões ambientais, entretanto, nenhum deles/as se declarou aliado ao ESP e a uma carta de intenções que visa tirar o pensamento crítico sobre o meio ambiente das escolas.

De acordo com o site Rede Brasil Atual (2019), em abril de 2019, a gestão Bolsonaro afirmou "fazer uma limpa no IBAMA e no ICMBio", demitindo os funcionários da área de fiscalização e desmontando as agendas das políticas ambientais conquistadas nas últimas três décadas. O Presidente propõe a flexibilização das licenças ambientais, a regulamentação de garimpos em unidades de conservação e em terras indígenas demarcadas, o avanço do agronegócio sobre os Biomas nacionais, 


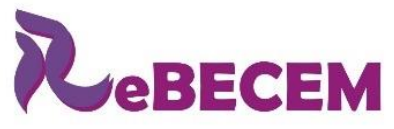

DOI: http://dx.doi.org/10.33238/ReBECEM.2019.v.3.n.3.23389
Revista Brasileira de Educação em

Ciências e Educação Matemática

especialmente o Amazônico. O atual Ministro do Meio Ambiente, Ricardo Salles, desfez dois conselhos do Fundo Amazônia e impõe retaliações às ajudas internacionais para a conservação da Floresta e para os investimentos em estratégias de defesa ambiental (GAZETA DO POVO, 2019). Não obstante, ainda é incentivada a liberação excessiva de agrotóxicos prejudiciais à água e ao solo, porém veementemente defendidos pela Ministra da Agricultura Tereza Cristina e por bolsões do agronegócio que desejam expandir as monoculturas e a pecuária.

Essas questões se afinam com a expansão econômica do país sem a preocupação com as agendas ambientais e o equilíbrio ecológico. São temas que envolvem, para a sua compreensão, o conhecimento das disciplinas de Ciências e Biologia (como também de Geografia e História) sobre fatores bióticos, abióticos, nichos ecológicos, adaptação dos seres vivos, dinâmicas de ecossistemas, mas, também, requerem uma compreensão política para a análise da correlação economia versus ambiente, para o entendimento das políticas públicas ambientais, para formulação de opiniões, posturas críticas, posturas defensivas, proposições de ideias e adoção de medidas de combate aos abusos e impactos ecológicos.

O ESP idealiza que as escolas não realizem discussões com vieses políticos em salas de aulas. Essa é uma medida que esvaziará a Educação Ambiental, pois ela não se atrela à apenas um entendimento técnico ou biológico. Como um tema transversal ela está amplamente relacionada com as ações políticas. Se adotada a perspectiva do ESP, os alunos terão a abordagem feita de modo superficial, sem a correlação com os fatos atuais e políticos que se intersectam com as tomadas de decisões para as agendas ambientais. E os/as estudantes poderão incorrer na adoção de explicações equivocadas e falsas, como, por exemplo, a adoção das correntes que negam o impacto dos poluentes na atmosfera terrestre e o aumento das temperaturas médias no Planeta ao longo das últimas décadas, ou seja, corre-se o risco de se fomentar a adesão ao negacionismo do aquecimento global, do efeito estufa e dos demais problemas climáticos na Terra.

Nessa perspectiva, o ESP restringiria o desenvolvimento de um pensamento crítico sobre nossas relações com os meios ambientes, levando os/as alunos/as a pensarem que os governos não têm nenhum papel quanto aos impactos ambientais, que o crescimento econômico é mais importante que o equilíbrio ecológico e a manutenção da vida planetária e que as possibilidades conscientes e sustentáveis de uso dos recursos ambientais (FIGURA 5). 
DOI: http://dx.doi.org/10.33238/ReBECEM.2019.v.3.n.3.23389

Figura 5: Reportagem tecendo críticas contra o Ambientalismo assinada pelo articulador do ESP Fábio Blanco

Desconfia de quem se mostra demais solícito com as crianças, disposto a
ensiná-las nos caminhos certos da vida moderna e a discipliná-las em um
pensamento coerente com o que há de mais politicamente correto. Não deixes
teus filhos à mercế dos educadores, das políticas educacionais e dos currículos
escolares; eles não existem para tornar tuas crianças boas, mas moldadas
conforme à imagem e semelhança dos poderes deste mundo.
Quando vejo, como vi em uma reportagem na tv, uma ecologista dizendo que
concentrava seu trabalho de divulgação nas crianças, por serem elas um grande
instrumento propagador das idéias ambientalistas, onde, talvez, a maioria das
pessoas tenham visto amor, bondade e as melhores intençôes, para mim, era
como se o próprio Satanás estivesse, esfregando as mãos, avisando que eles,
os pequenos, lhes pertencia.

Fonte: www.escolasempartido.org

Embora não tão diretamente abordados pelo ESP quanto os temas Origem do Universo e da Vida, gênero, Sexualidade e Educação Ambiental, quando pensamos o ensino de genética, o ensino da saúde, o tratamento com células e tecidos, a doação de órgãos para o salvamento de vidas, podemos dizer que há uma interferência acrítica em relação ao entendimento dos mesmos, uma vez que esses assuntos, por estarem implicados em defensivas ou posições religiosas que lhes negam, não poderão ser discutidos com debates plurais nas escolas, já que o ESP postula que os princípios religiosos e morais devem ser respeitados acima das convicções científicas.

A Vacinação para a prevenção do "Papiloma vírus humano" (HPV), por exemplo, é uma dessas questões polêmicas que envolvem a compreensão da saúde pública e o combate às concepções pseudocientíficas. Alguns familiares se declaram contra a vacina em jovens em idade sexual-reprodutiva, pois alegam que o processo de tratamento com a vacina não tem eficácia comprovada, que a mesma pode levar a casos de morte e, no quesito moral, que a vacinação seria um imperativo para a indução do amadurecimento sexual de filhas mulheres. Essa é uma explicação equivocada que se difunde conforme se propaga o senso comum de alguns grupos religiosos contrários à imunização. 
DOI: http://dx.doi.org/10.33238/ReBECEM.2019.v.3.n.3.23389

$\mathrm{Na}$ escola aprendemos que a vacina contra o HPV e outros processos de imunização não se associam a esses efeitos de morte ou indução sexual. As campanhas contra o HPV são de fundamental importância para mulheres, principalmente na faixa etária de 9 a 12 anos, para se evitar a infecção viral nas relações sexuais que vierem a acontecer e para que tomem os cuidados e utilizem os preservativos devidos. Em muitas famílias, persiste, ainda, a ideia de que as meninas não irão se iniciar sexualmente antes do casamento. Por essa ótica, então, estaria a escola impedida de esclarecer os/as estudantes sobre o risco de contaminações com HPV e sobre o aumento de casos de IST e de câncer do colo do útero?

Na lógica do ESP, a escola não se envolveria com a realização de Campanhas de Vacinação, respeitando a interposição religiosa de cada estudante. Esse fato é preocupante, pois, cada vez mais, a vida sexual em adolescentes tem se iniciado mais cedo. Além disso, há correntes teológicas fundamentalistas contrárias a todos os tipos de vacinação. Então, a escola se calaria diante dessas convicções e apagaria os conhecimentos científicos sobre microrganismos, imunização e recursos tecnológicos que nos auxiliam na prevenção de doenças e na saúde individual e populacional?

Vale lembrar que alguns credos pentecostais e algumas alas conservadoras da Igreja Católica também se posicionam contrários ou reticentes ao tratamento com transplante de órgãos e tecidos, uso de células-tronco embrionárias, à fertilização artificial, por acreditarem que essas práticas violam a vida natural criada por Deus.

Nesse caso, professores/as não poderiam se posicionar sobre o uso dessas tecnologias e nem promover o debate sobre os avanços do conhecimento científico, suas potencialidades, seus limites, a relação econômica para a aquisição de uma tecnologia de tratamento ou de prevenção, nem mesmo sobre a vida? O que a escola faria com o conhecimento científico postulado em seus currículos para se posicionar os/as estudantes sobre os usos da ciência na vida cotidiana? Como ficariam os apontamentos das contradições presentes em explicações religiosas, nas concepções equivocadas e nos sensos comuns referentes às novas tecnologias para os tratamentos de saúde? Provavelmente, abolidos dos currículos escolares.

Ainda no Ensino de Ciências e Biologia, quando se abordam discussões genéticas, o Conceito de $\operatorname{Raça}^{9}$ e as implicações Étnico-raciais, que são transversais às

\footnotetext{
${ }^{9} \mathrm{Na}$ atualidade, os avanços da genética molecular, das pesquisas de sequenciamento do genoma humano, dos estudos biogeográficos, antropológicos e da ancestralidade de nossa espécie (PENA; BIRCHAL, 2006) colocam em cheque os estigmas e categorias - aportados em usos equivocados da Biologia e no racismo
} 
DOI: http://dx.doi.org/10.33238/ReBECEM.2019.v.3.n.3.23389

compreensões biológicas, podem ser barrados pelo ESP. De acordo com a BNCC (Ensino

Fundamental e Médio), tais temas estão contemplados pelo Eixo Vida e Evolução, que:

[...] propõe o estudo de questões relacionadas aos seres vivos (incluindo os seres humanos), suas características e necessidades, e a vida como fenômeno natural e social, os elementos essenciais à sua manutenção e à compreensão dos processos evolutivos que geram a diversidade de formas de vida no planeta [...] (BRASIL, 2018, p. 326).

No Ensino Fundamental, na disciplina de Ciências, a BNCC (2018), por exemplo, estabelece que o aluno deva comparar características físicas entre os colegas, reconhecendo a diversidade e a importância da valorização, do acolhimento e do respeito às diferenças, permitindo ao professor abordar a questão do racismo e do preconceito como um todo. No Ensino Médio, na disciplina de Biologia, o documento ainda aponta que os alunos devem identificar, analisar e discutir vulnerabilidades vinculadas às vivências e aos desafios contemporâneos aos quais as juventudes estão expostas, considerando os aspectos físico, psicoemocional e social, pensando na promoção da saúde individual, coletiva e no bem-estar social.

Embora saibamos que do ponto de vista genético não há base científica para se formular o conceito de Raças humanas, a abordagem racial, incluindo os debates sobre os períodos históricos nos quais se havia a crença de que as diferenças biológicas demarcadas serviam para justificar discriminação, exploração e violências contra determinados grupos (PENA; BIRCHAL, 2006), os debates sobre as diferenças fenotípicas nas etnias e as discussões sobre a relevância das cotas raciais estariam comprometidos com os imperativos do ESP.

Nesse quesito, os/as docentes não poderão discutir em sala de aula a questão da discriminação dos/as negros/as em períodos como a Escravidão, a Ditadura Militar e na restrição à ascensão social quando comparados aos brancos, e nem que as cotas se colocam como um mecanismo de políticas públicas para a minimização das desigualdades históricas entre os dois grupos. Expoentes do ESP contrários às cotas alegam que elas sejam um meio de facilitação para os negros; também apontam que as escolas não devem se ater a essas discussões porque ela é um lugar neutro, no qual a discriminação seria uma invenção e um discurso dos partidos de esquerda (FIGURA 6).

científico - para especificar raças humanas. Em nossa era geológica, a quantidade de diferenças existentes entre as populações humanas é tão ínfima que não permite categorizar nossa espécie em subespécies. Sob essa prerrogativa, o conceito de raça, em humanos, não deve ser confundido com os conceitos de subespécie e de variedade usados para classificar outros seres vivos. 
Figura 6: Crítica acusando o documentário "Uma conversa sobre o racismo" de doutrinação ideológica

\section{EUA - Uma conversa sobre racismo}

Parece que não, mas esse documentário tem tudo a ver com doutrinação ideológica nas escolas. Assista até o final, e você vai ver

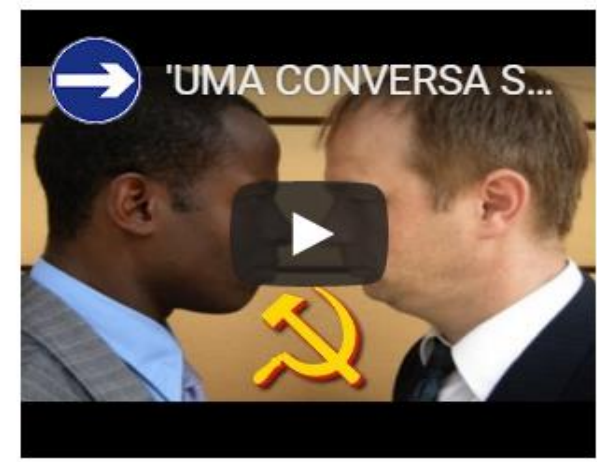

Fonte: www.escolasempartido.org

É de fundamental importância que o professor aborde as questões históricas atreladas aos racismos e preconceitos contra negros, exemplificando que questões hormonais, variações fenotípicas, adaptações ambientais não são atributos para se inferiorizar a inteligência e as aptidões. O ESP, contudo, toma a questão como doutrinação e nega a veracidade histórica dos períodos de exploração do trabalho e social das pessoas negras.

Logo, para o ESP essas indagações científicas não são importantes, uma vez que sua proposta visa restringir os conhecimentos escolares e o Ensino de Ciências e Biologia a conhecimentos técnicos sem relação com a vida biológica ou com a vida em sociedade, sem se importar com as compreensões políticas e com as transformações no mundo e nas pessoas, sem se dispor a discutir condutas, atitudes e valores para a boa convivência e para o respeito com os/as diferentes.

\section{Considerações finais}

O Movimento ESP se coloca como um entrave para a liberdade de expressão dos docentes em sala de aula, além de representar um fator limitante para o desenvolvimento do pensamento crítico dos/as alunos/as. Tem se tornado uma bandeira política de partidos conservadores alinhados a pensamentos reacionários e à retirada das questões de cunho social da escola. 
DOI: http://dx.doi.org/10.33238/ReBECEM.2019.v.3.n.3.23389

Seu intuito é se tornar uma política educacional via sua inserção na Constituição Federal, na modificação da LDBEN/1996, na fiscalização da produção de materiais e livros didáticos e, no dia a dia das escolas, na interferência das atuações pedagógicas docentes controlando o ensino de conteúdos escolares e produzindo sujeitos alienados/as. Nesse sentido, é fundamental destacar que o ESP trará impactos negativos para a Educação Básica e para a escola pública, estabelecendo uma política de censura e do não à liberdade de pensamento, expressão e opinião.

Em relação ao Ensino de Ciências e Biologia, vários conteúdos serão impactados com a adoção do ESP. Temáticas como "Terra e Universo" e "Origem da Vida" poderão ser reduzidas às concepções religiosas e contempladas como teorias distantes dos paradigmas aceitos pela ciência. Questões ecológicas, tais como Impactos Ambientais, uso excessivo de agrotóxicos, desmatamento, entre outros assuntos, não poderão ser instigados junto aos/as alunos/as, por serem tomados como posicionamentos políticos que não carecem de discussão nas escolas.

Sabemos, entretanto, que nem sempre os/as familiares discutem o meio em que os/as alunos estudam e os tema econômicos, políticos, sexuais, sociais e ambientais em casa. Por isso, a importância da escola para a socialização e a formação cidadã dos/as estudantes.

Pari passu, desde 2014, o ESP se alia às posições dogmáticas de grupos religiosos e acredita que discutir Gênero, Sexualidade e Diversidade Sexual nas escolas é uma maneira de incitar a vida sexual precoce de jovens. Torna-se preocupante a criação de impedimentos para se coibir professores/as das discussões sobre prevenção, sobre abusos e violências sexuais, sobre as identidades LGBT e sobre os racismos e as violências. $\mathrm{O}$ movimento visa restringir a Educação Sexual e a formação de princípios de valores, respeito e reconhecimento para com as pessoas diferentes, as identidades LGBT e as diversidades étnicas, culturais e sociais às concepções dos grupos familiares.

Conforme aponta Carvalho (2019), no entanto, essa tática do ESP não se restringe apenas às posturas conservadoras e reacionárias de pequenos grupos. Trata-se de algo maior, de algo que acontece ao nível das Políticas de Governo e de Estado, que visa minar o pensamento crítico para a manutenção de normas vigentes, do status quo, dos grupos hegemônicos e para a criação de um projeto de escola no qual o pensamento científico poderá ser banido.

É importante destacar que o ESP tem se instalado em PL e em redes sociais como uma maneira de cercear a liberdade de expressão tanto de educadores/as quanto de 


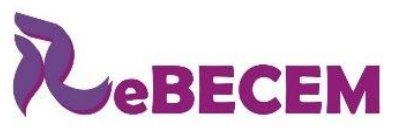

Revista Brasileira de Educação em

Ciências e Educação Matemática

DOI: http://dx.doi.org/10.33238/ReBECEM.2019.v.3.n.3.23389

estudantes, o que acarretará num enorme prejuízo para os ambientes, os currículos, os processos de formação e as vivências escolares. Seu pior efeito é a deturpação do ensino e o estabelecimento de um sistema de vigília que representa a retirada da autonomia da escola pública e o controle do pensamento humano.

Os conhecimentos científicos têm importância para a construção ética das relações sociais e para o entendimento da vida. Logo, eles também são fundamentais para se evitar que posições arbitrárias se imponham coletivamente. O ESP vai contra esse papel da escola em ser formadora da opinião crítica, da cidadania e do respeito às diferenças ao lhe impor o postulado da mera transmissão de conteúdos curriculares sem abarcar temas atuais, do contexto de vida dos/as estudantes e da História.

Se incorporado como Lei, o ESP trará impactos ao Ensino de Ciências e Biologia, assim como de outras áreas do conhecimento, porque impedirá as discussões plurais que envolvam posicionamentos políticos, sociais e culturais para se compreender temas como as políticas públicas, o Meio Ambiente, a Origem do Universo, o Corpo e a Sexualidade, a Diversidade Sexual e cultural e Saúde, tornando-se a Lei que amordaça as escolas.

Por fim, podemos elucidar que, no âmbito do Ensino de Ciências e Biologia como um campo de conhecimento historicamente consolidado, fruto das lutas de pesquisadores/as e professores/as, das remodelações curriculares e do posicionamento cidadão da escola, o ESP representaria um retrocesso epistemológico, uma vez que postula tanto o Ensino quanto a Ciência como produções neutras, imutáveis, inquestionáveis, desarticuladas de grupos econômicos e políticos e totalmente isentas de interesses sociais. Por essa ótica, o Ensino de Ciências e Biologia pode se tornar, portanto, uma mera abordagem dos fatos e uma arbitrariedade de informações conteudísticas sem o compromisso com a formação social dos/as estudantes na educação básica.

\section{Referências}

ALTMANN, H. Orientação sexual nos parâmetros curriculares nacionais. Revista Estudos Feministas, Florianópolis, v. 9, n. 2, p. 575-585, 2001.

ANUNCIATTO, P. Menor do que parece: Escola sem Partido. Revista Nova Escola, São Paulo, n. 311, s/p, 2017.

BAGDONAS, A.; AZEVEDO, H. L. O Projeto de Lei "Escola sem Partido" e o Ensino de Ciências. ALEXANDRIA: R. Educ. Ci. Tec., Florianópolis, v. 10, n. 2, p. 259-277, nov., 2017.

BRASIL. Ministério da Educação. Base Nacional Comum Curricular (BNCC). Educação é a Base. Brasília, MEC/CONSED/UNDIME, 2018. Disponível em: 
DOI: http://dx.doi.org/10.33238/ReBECEM.2019.v.3.n.3.23389

http://basenacionalcomum.mec.gov.br/images/BNCC_EI_EF_110518_versaofinal_site.pdf.

Acesso em: 29 set. 2019.

BRASIL. Constituição da República Federativa do Brasil (1988). Promulgada em 05 de outubro de 1988. Disponível em:

http://www.planalto.gov.br/ccivil_03/constituicao/constituicao.htm. Acesso em: 10 ago. 2019.

BRASIL. Câmara dos Deputados. Projeto de Lei n. 246, de 04 de fevereiro de 2019. Institui o Programa Escola sem Partido. Brasília, DF, 04 fev. 2019. Disponível em:

https://www.camara.leg.br/proposicoesWeb/fichadetramitacao?idProposicao=2190752. Acesso em: 20 set. 2019.

BRASIL. Secretaria de Educação Média e Tecnológica. Parâmetros Curriculares Nacionais: PCN Ensino Fundamental. Brasília: MEC, SEMTEC, 1997.

CARVALHO, F. A. Quando a exceção torna-se regra totalitária: o cruzamento do movimento Escola sem Partido com a persecução aos estudos de gênero e à educação para as sexualidades. Revista Educação e Linguagens, Campo Mourão, v.8, n. 14, s/p, 2019.

CARVALHO, F. A.; BERTOLLI-FILHO, C. Sexualidade e educação sexual: enunciações e dispositivos nos contextos de ensino de ciências. In: ENCONTRO NACIONAL DE PESQUISA EM ENSINO DE CIÊNCIAS, 8., 2011, Campinas (SP). Anais... Campinas: ABRAPEC/NUTES/UNICAMP, 2011, p. 1-10.

CARVALHO, F. A.; POLIZEL, A. L.; MAIO, E. R. Uma escola sem partido: dicursividade, currículos e movimentos sociais. Semina: Ciências Sociais e Humanas, Londrina, v. 37, n. 2, p. 193-210, jul./dez. 2016.

DEMIER, F. Depois do golpe: a dialética da democracia blindada no Brasil. Rio de Janeiro: Mauad X, 2017.

ESCOLA SEM PARTIDO. 2019. Disponível em: http://www.escolasempartido.org. Acesso em: 19 ago. 2019.

GAZETA DO POVO. O "Roubo" em Noronha e mais 5 polêmicas ambientais do governo Bolsonaro. 2019. Disponível em: https://www.gazetadopovo.com.br/republica/polemicasgoverno-jair-bolsonaro-ricardo-salles-meio-ambiente/. Acesso em: 20 set. 2019.

JUNQUEIRA, R. D. "Ideologia de gênero": a gênese de uma categoria política reacionária - ou: a promoção dos direitos humanos se tornou uma "ameaça à família natural"? In: RIBEIRO, P. R. C; MAGALHÃES, J. C. (org.). Debates contemporâneos sobre educação para a sexualidade. Rio Grande: Editora da Furg, 2017. p. 25-52.

LOURO, G. L. Gênero, sexualidade e educação: uma perspectiva pós-estruturalista. 5. ed. Petrópolis: Vozes, 1997.

MAIO, E. (org). Gênero e Sexualidade: Interfaces Educativas. Curitiba: Appris, 2018.

MIGUEL, L. F. Da "doutrinação marxista" à "ideologia de gênero": Escola Sem Partido e as leis da mordaça no parlamento Brasileiro. Direito e Práxis, Rio de Janeiro, v. 7, n. 15, p. 59062, 2016.

PENA, S. D. J.; BIRCHAL, T. S. A inexistência biológica versus a existência social de raças humanas: pode a ciência instruir o etos social. Revista USP, São Paulo, n. 68, p. 10-21, 2006. 
DOI: http://dx.doi.org/10.33238/ReBECEM.2019.v.3.n.3.23389

REDE BRASIL ATUAL. Governo Bolsonaro libera mais 63 agrotóxicos; 15 extremamente tóxicos. 2019. Disponível em: https://www.redebrasilatual.com.br/ambiente/2019/09/bolsonaromais-63-agrotoxicos/. Acesso em: 20 set. 2019.

REIS, T. A “ideologia” de gênero, a equidade e os planos de educação. 2015. Disponível em: http://www.anped.org.br/news/a-ideologia-de-genero-a-equidade-e-os-planos-de-educacao. Acesso em: 20 set. 2019.

SCOTT, J. W. Gênero: uma categoria útil de análise histórica. Educação e Realidade, Porto Alegre, v. 20, n. 2, p. 21. jul./dez. 1995.

SELLES, S. E. A polêmica instituída entre ensino de evolução e criacionismo: dimensões do público e do privado no avanço do neoconservadorismo. Ciência \& Educação, Bauru, v. 22, n. 4, p. 831-835, 2016.

SILVA, E. et al. A "ideologia de gênero" e a "Escola sem Partido": Faces de uma mesma moeda em ações políticas conservadoras no Brasil e no Espírito Santo. Revista Inter Ação, Goiânia, v. 43, n. 3, p. 615-631, 2018.

SILVEIRA, Z. S. Onda conservadora: o emergente movimento Escola sem Partido. In: BATISTA, E. L.; ORSO, P. J.; LUCENA, C. (org.). Escola sem partido ou a escola da mordaça e do partido único a serviço do capital. Uberlândia: Navegando Publicações, 2019. p. 26-37.

SOUZA, A L. S. et al. A ideologia do movimento Escola sem Partido: 20 autores desmontam o discurso. São Paulo: Ação Educativa, 2016.

VYGOTSKY, L. S. Pensamento e linguagem. 2. ed. São Paulo: Martins Fontes, 1989.

Recebido em: 07 de outubro de 2019.

Aceito em: 28 de novembro de 2019. 